\title{
Management of Conjunctival Melanoma: Critical Assessment of Sentinel Lymph Node Biopsy
}

\author{
Hassan A. Aziz Brian R. Gastman Arun D. Singh \\ Department of Ophthalmology, Cole Eye Institute, Cleveland Clinic Foundation, \\ Cleveland, Ohio, USA
}

\section{Key Words}

Conjunctival melanoma - Aggressive form · Sentinel lymph node biopsy

\begin{abstract}
Conjunctival melanoma (CoM) is a rare and aggressive form of melanoma. There is a lack of consensus on a unified management plan for this disease. Recently, a few centers have adopted the regional sentinel lymph node biopsy into the staging process of CoM. This study presents a critical assessment of the role of sentinel lymph node biopsy in CoM and presents a simplified management algorithm based on high-risk clinical and pathological features.
\end{abstract}

(C) 2015 S. Karger AG, Basel

\section{Introduction}

Conjunctival melanoma ( $\mathrm{CoM})$ is a rare and aggressive cancer that constitutes only $5-7 \%$ of all primary ocular melanomas [1,2]. The Surveillance, Epidemiology, and End Results (SEER) noted a marked increase in the incidence of CoM, especially amongst white males, and that is most likely linked to an increase in UV light exposure [3]. CoM may originate from a nevus, primary acquired melanosis or arise de novo. Depending on its origin, size, location, histological features, lymph node involvement and systemic metastasis, the prognosis differs greatly. At 10 years' follow-up, the recurrence and mortality rates could be as high as 62 and $30 \%$, respectively [4-6].

Like most rare diseases, the management of CoM lacks consensus on staging, systemic workup and follow-up protocol after the excision of the conjunctival tumor. Moreover, conducting multicenter trials with a large number of patients poses a great challenge. The 


\section{Ocular Oncology}

and Pathology

Fig. 1. a Slit-lamp photo of the right eye revealing a bulbar conjunctival mass with associated coarse pigment granules. b SPECT/CT image of the head and neck highlighting the enhancement of the SLN in the right parotid gland after subconjunctival technetium-99m injection.

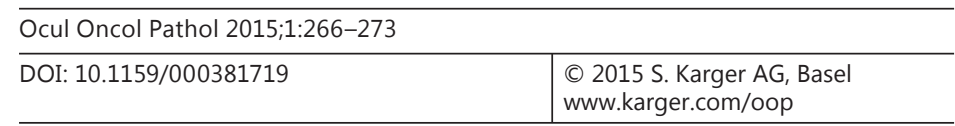

Aziz et al.: Management of Conjunctival Melanoma: Critical Assessment of Sentinel Lymph Node Biopsy

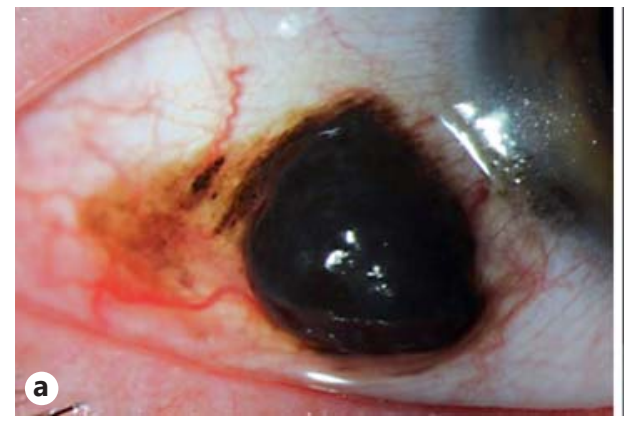

current management of most patients with CoM includes tumor excision and cryotherapy to the margins [7]. Adjuvant topical chemotherapy or brachytherapy could be used in diffuse or deep infiltrative disease [8-11]. After excision, the patient is observed periodically for local or systemic recurrence. Once overt, systemic metastasis occurs and the prognosis is poor [12]. Sentinel lymph node (SLN) biopsy for staging and prognostication of the disease is only done in a few centers around the world [13-22]. Its impact on long-term survival is not known.

The purpose of this paper is to propose a management protocol of CoM by presenting a relatively common scenario that gets referred to an ocular oncology center. The protocol is based on published outcomes of patients who underwent SLN biopsy.

\section{Case Presentation}

A 51-year-old man was referred with a conjunctival lesion of the right eye that was noted to be growing in size over the course of a year. He reported that the lesion had been present for the past 2 years, but had grown significantly in the last 6 months. On presentation, the patient had a visual acuity of 20/20 in the right eye and 20/70 in the left eye (he had a history of an epiretinal membrane). Intraocular pressures were 13 $\mathrm{mm} \mathrm{Hg}$ in both eyes. An examination of the right eye revealed a bulbar conjunctival mass measuring $5 \times 3 \times$ $2 \mathrm{~mm}$ in size, located $1 \mathrm{~mm}$ posterior to the corneoscleral limbus, extending from 8 to 9 o'clock (fig. 1). Coarse pigment granules were present and surrounding the tumor, extending $1 \mathrm{~mm}$ anteriorly into the cornea and $4 \mathrm{~mm}$ posterior to the posterior edge of the tumor. His fundus examination was otherwise within normal limits. The left eye was normal.

The patient was then scheduled for a combined procedure of conjunctival tumor excisional biopsy, map biopsies, cryotherapy and defect repair using an amniotic membrane graft and an SLN biopsy to stage the melanoma.

\section{Procedure}

Two hours prior to surgery, $0.5 \mathrm{ml}$ of technetium-99m was injected subconjunctivally at the site of the lesion and SPECT/CT imaging was done to identify the SLN (fig. 1). During the first segment of surgery, viscoelastic was used to cover the unaffected cornea. Absolute alcohol was placed over the affected corneal epithelium and adjacent, $1 \mathrm{~mm}$ of normal epithelium was then copiously irrigated for $1 \mathrm{~min}$. The epithelium was then scraped towards the limbus without disturbing the underlying Bowman's layer and stroma. Attention was then shifted to the bulbar component where a partial thickness scleral flap (30\%) was used to dissect the tumor with $3 \mathrm{~mm}$ margins. The scleral dissection was performed out to the limbus. Finally, the corneal, limbal, and conjunctival components were excised as a single piece. Additionally, 1-mm strips of 3 conjunctival margins were then further excised and sent to pathology. Cryotherapy (double freeze thaw) was then applied to the conjunctival margins in an attempt to eradicate any microscopic disease. An amniotic membrane was then used to cover the scleral bed, and subconjunctival indocyanine green angiography was injected $(0.5 \mathrm{ml})$ at the end of the first part of the procedure around the site of the tumor. Next, the SLN biopsy portion of the procedure was performed and the locations of the SLNs were confirmed intraoperatively by using both a 
Table 1. Five-year recurrence and metastasis rates based on the AJCC classification of conjunctival melanoma [24, 25]

\begin{tabular}{|c|c|c|c|c|c|}
\hline \multicolumn{2}{|c|}{ Primary tumor $(\mathrm{T})$} & \multicolumn{2}{|c|}{ Five-year recurrence rate, $\%$} & \multicolumn{2}{|c|}{ Five-year metastasis rate, $\%$} \\
\hline & & \multirow[t]{2}{*}{ Shields et al. } & \multirow[t]{2}{*}{ Yousef et al. } & \multirow[t]{2}{*}{ Shields et al. } & \multirow[t]{2}{*}{ Yousef et al. } \\
\hline $\mathrm{Tx}$ & Primary tumor cannot be assessed & & & & \\
\hline $\mathrm{T}(0)$ & No evidence of primary tumor & - & - & - & - \\
\hline $\mathrm{T}$ (is) & $\begin{array}{l}\text { Malignant melanoma confined to conjunctival } \\
\text { epithelium }\end{array}$ & - & - & 19 & - \\
\hline $\mathrm{T} 1$ & Malignant melanoma of the bulbar conjunctiva & 44 & 11 & 27 & - \\
\hline T1a & $<1$ quadrant & 34 & 17 & - & 20 \\
\hline $\mathrm{T} 1 \mathrm{~b}$ & $>1$ but $<2$ quadrants & 52 & 5 & 44 & - \\
\hline $\mathrm{T} 1 \mathrm{c}$ & $>2$ but $<3$ quadrants & 47 & 6 & - & 33 \\
\hline T1d & $>3$ quadrants & 60 & 20 & - & - \\
\hline \multirow[t]{2}{*}{$\mathrm{T} 2$} & Malignant melanoma of palpebral conjunctiva, & & & & \\
\hline & forniceal conjunctiva, and/or caruncle & 78 & 35 & 33 & - \\
\hline $\mathrm{T} 2 \mathrm{a}$ & $<1$ quadrant but not involving caruncle & - & 40 & - & - \\
\hline $\mathrm{T} 2 \mathrm{~b}$ & $>1$ quadrant but not involving caruncle & 83 & 49 & 50 & - \\
\hline $\mathrm{T} 2 \mathrm{c}$ & $<1$ quadrant and involving caruncle & 25 & 40 & - & - \\
\hline $\mathrm{T} 2 \mathrm{~d}$ & $>1$ quadrant and involving caruncle & 80 & 38 & - & - \\
\hline T3 & Malignant melanoma with local invasion & 76 & 42 & 75 & 63 \\
\hline T3a & Globe & - & - & - & - \\
\hline $\mathrm{T} 3 \mathrm{~b}$ & Eyelid & 75 & 39 & 50 & - \\
\hline $\mathrm{T} 3 \mathrm{c}$ & Orbit & - & - & 80 & 80 \\
\hline T3d & Paranasal sinus & - & - & 100 & 100 \\
\hline $\mathrm{T} 4$ & Malignant melanoma with intracranial invasion & - & - & - & - \\
\hline
\end{tabular}

gamma probe and the SPY Elite system (LifeCell, Bridgewater, N.J., USA) to detect the technetium-99m and indocyanine green angiography dyes, respectively (described previously by the authors) [16].

The results of the conjunctival biopsy confirmed a malignant melanoma of $1.2 \mathrm{~mm}$ Breslow thickness with $>1$ mitotic figure per $1 \mathrm{~mm}^{2}$. It was of mixed cell type and was negative for ulceration. The margins and the SLN biopsies were all negative for melanoma. The patient was reassured and is being followed up every 3 months.

\section{Discussion}

In 2010, the American Joint Committee on Cancer (AJCC) published a new staging system of CoM [23]. Retrospective studies have confirmed the validity of the new staging system and showed that, as the stage of CoM progresses, the recurrence and metastasis rates increase progressively (table 1) [24, 25]. Overall, the major clinical prognostic indicators of CoM are TNM staging (including nonbulbar location and thickness of the tumor) and origin of the tumor (primary acquired melanosis and de novo vs. nevus) [25-27].

SLN biopsy for CoM staging is seldom performed, even though regional lymph nodes are the first site of metastasis in most cases of CoM [7, 28, 29]. Werschnik and Lommatzsch [12] reported that, once the lymph nodes are overtly involved in CoM, the prognosis is poor. These findings are similar to observations in cutaneous melanoma that have indicated that the strongest predictor of survival is the presence or absence of regional lymph node metastases $[30,31]$. The presence of lymph node metastases decreases the 5 -year survival rate by approximately $40 \%$ when compared to those who have no evidence of lymph node metastases [32].

SLN biopsy detects micrometastases when conventional methods of lymph node screening (e.g. ultrasound) may not, as the size of the lymph node is not enlarged with micro- 
Aziz et al.: Management of Conjunctival Melanoma: Critical Assessment of Sentinel Lymph Node Biopsy

Table 2. Indications and characteristics of the patients who underwent SLN biopsies for CoM

\begin{tabular}{|c|c|c|c|c|c|c|}
\hline Reference & $\mathrm{n}$ & $\begin{array}{l}\text { Criteria for SLN } \\
\text { biopsy }\end{array}$ & $\begin{array}{l}\text { Positive } \\
\text { SLN (\%) }\end{array}$ & $\begin{array}{l}\text { Thickness of CoM } \\
\text { tumors with } \\
\text { negative SLN Bx }\end{array}$ & $\begin{array}{l}\text { Thickness of CoM } \\
\text { tumors with } \\
\text { positive SLN Bx }\end{array}$ & $\begin{array}{l}\text { Location of CoM } \\
\text { tumors with } \\
\text { positive SLN Bx }\end{array}$ \\
\hline $\begin{array}{l}\text { Esmaeli } \\
\text { et al. [21] }\end{array}$ & 1 & Not specified & $0 / 1(0)$ & $0.95 \mathrm{~mm}$ & $\mathrm{~N} / \mathrm{A}$ & $\mathrm{N} / \mathrm{A}$ \\
\hline $\begin{array}{l}\text { Wilson } \\
\text { et al. [19] }\end{array}$ & 1 & Not specified & $0 / 1(0)$ & $\begin{array}{l}\text { Not specified } \\
\text { (recurrence tumor } \\
\text { from PAM) }\end{array}$ & $\mathrm{N} / \mathrm{A}$ & $\mathrm{N} / \mathrm{A}$ \\
\hline $\begin{array}{l}\text { Esmaeli } \\
\text { et al. [20] }\end{array}$ & 1 & Not specified & $1 / 1(100)$ & $\mathrm{N} / \mathrm{A}$ & $3.1 \mathrm{~mm}$ & Paralimbal \\
\hline $\begin{array}{l}\text { Nijhawan } \\
\text { et al. [15] }\end{array}$ & 5 & $\begin{array}{l}\text { Thickness ( } \geq 1 \mathrm{~mm} \text { ) } \\
\text { Undetermined } \\
\text { thickness } \\
\text { (e.g. previously } \\
\text { excised CoM } \\
\text { at a different } \\
\text { institution) }\end{array}$ & $1 / 5(20)$ & $\begin{array}{l}0.3 \mathrm{~mm} \\
1.2 \mathrm{~mm} \\
1.2 \mathrm{~mm} \\
\text { unknown }\end{array}$ & $3.1 \mathrm{~mm}$ & Nonlimbal \\
\hline $\begin{array}{l}\text { Baroody } \\
\text { et al. [13] }\end{array}$ & 2 & Not specified & $2 / 2(100)$ & $\mathrm{N} / \mathrm{A}$ & $\begin{array}{l}4.5 \mathrm{~mm} \\
8 \mathrm{~mm}\end{array}$ & $\begin{array}{l}\text { Nonlimbal } \\
\text { Nonlimbal }\end{array}$ \\
\hline $\begin{array}{l}\text { Savar } \\
\text { et al. [18] }\end{array}$ & 26 & $\begin{array}{l}\text { Thickness }(\geq 1 \mathrm{~mm}) \\
\text { Recurrence of CoM } \\
\text { Negative metastatic } \\
\text { staging }\end{array}$ & $4 / 26(15)$ & $\begin{array}{l}2.7 \mathrm{~mm} \\
(\text { range } 0.62-12.0)^{\mathrm{a}}\end{array}$ & $\begin{array}{l}2.1 \mathrm{~mm} \\
3.8 \mathrm{~mm} \\
5.2 \mathrm{~mm} \\
6 \mathrm{~mm}\end{array}$ & $\begin{array}{l}\text { Nonlimbal } \\
\text { Nonlimbal } \\
\text { Nonlimbal } \\
\text { Nonlimbal }\end{array}$ \\
\hline $\begin{array}{l}\text { Motomura } \\
\text { et al. [22] }\end{array}$ & 1 & Not specified & $0 / 1(0)$ & $3 \mathrm{~mm}$ & $\mathrm{~N} / \mathrm{A}$ & $\mathrm{N} / \mathrm{A}$ \\
\hline $\begin{array}{l}\text { Maalouf } \\
\text { et al. [17] }\end{array}$ & 2 & Not specified & $0 / 2(0)$ & $\begin{array}{l}1.2 \mathrm{~mm} \\
0.8 \mathrm{~mm}\end{array}$ & $\mathrm{~N} / \mathrm{A}$ & $\mathrm{N} / \mathrm{A}$ \\
\hline $\begin{array}{l}\text { Cohen } \\
\text { et al. [14] }\end{array}$ & $18 b$ & $\begin{array}{l}\text { Thickness }(\geq 2 \mathrm{~mm}) \\
\text { Nonlimbal location }\end{array}$ & $2 / 18(11)$ & $\begin{array}{l}2.0 \mathrm{~mm} \\
\text { (range 1.0-13.0) }\end{array}$ & $\begin{array}{l}2.2 \mathrm{~mm} \\
10 \mathrm{~mm}\end{array}$ & $\begin{array}{l}\text { Nonlimbal } \\
\text { Nonlimbal }\end{array}$ \\
\hline $\begin{array}{l}\text { Rubinstein } \\
\text { et al. [16] }\end{array}$ & 4 & $\begin{array}{l}\text { Thickness }(\geq 2 \mathrm{~mm}) \\
\text { Ulceration on } \\
\text { pathology } \\
\geq 1 \text { mitotic figure per } \\
\mathrm{mm}^{2}\end{array}$ & $0 / 4(0)$ & $\begin{array}{l}2.0 \mathrm{~mm} \\
3.4 \mathrm{~mm} \\
4.4 \mathrm{~mm} \\
4.4 \mathrm{~mm}\end{array}$ & $\mathrm{~N} / \mathrm{A}$ & $\mathrm{N} / \mathrm{A}$ \\
\hline Total & 61 & & $\begin{array}{l}10 / 61 \\
(16.4 \%)\end{array}$ & $\begin{array}{l}\text { Overall mean: } \\
2.4 \mathrm{~mm}\end{array}$ & $\begin{array}{l}\text { Overall mean: } \\
4.8 \mathrm{~mm}\end{array}$ & $\begin{array}{l}9 / 10(90 \%) \text { of } \\
\text { patients with } \\
\text { positive SNL } \\
\text { were non-limbal } \\
\text { in location }\end{array}$ \\
\hline
\end{tabular}

Bx $=$ Biopsy.

${ }^{\text {a }}$ Four patients with eyelid skin melanoma are included in the mean of tumor thickness with negative SLN biopsies. ${ }^{b} 4 / 22$ patients were excluded since the SLNs were not identified during the biopsy procedure.

metastases $[13,15]$. The procedure has a high safety profile with the most common complication being temporary weakness of the facial nerve that resolves spontaneously. Parotid sentinel node biopsy has a slight increase in the potential morbidity of facial nerve injury, albeit this rarely occurs when performed by an experienced surgeon [15]. 
Ocular Oncology
and Pathology

Table 3. High-risk features of $\mathrm{CoM}$

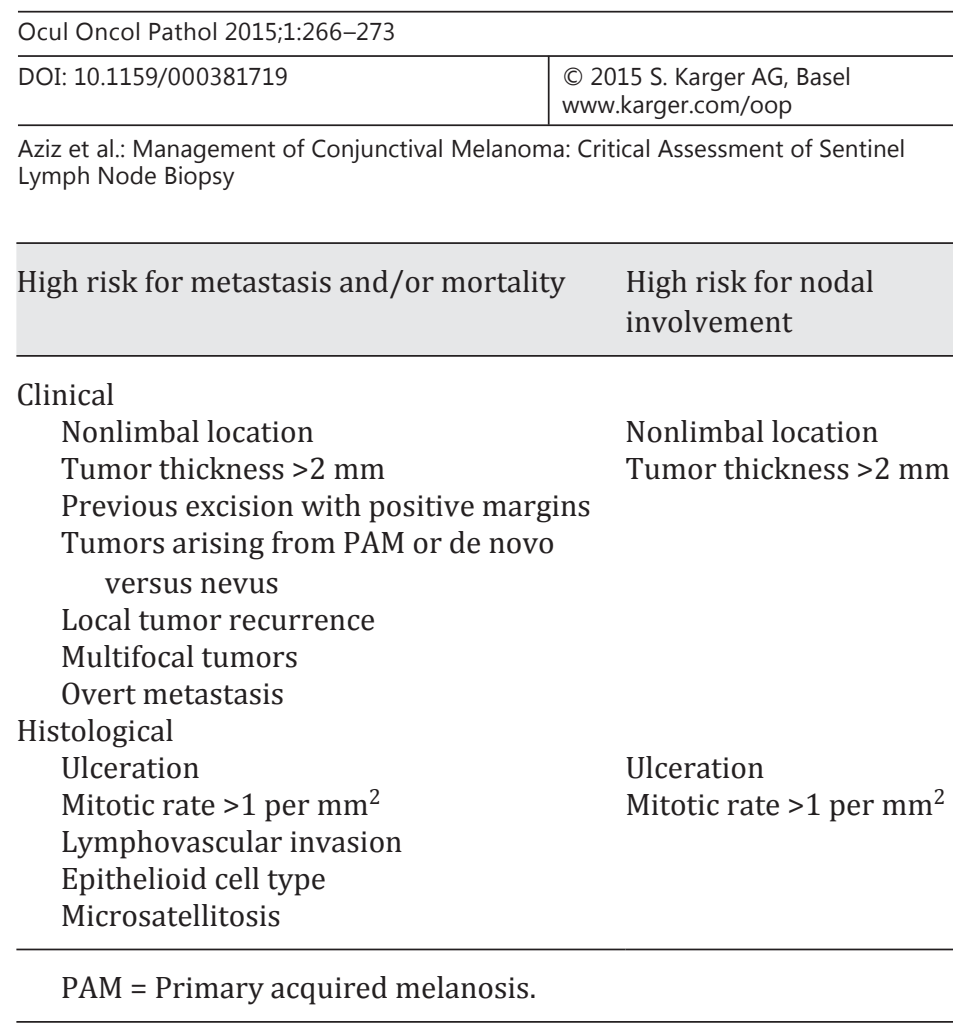

On the other hand, hematogenous spread without regional nodal involvement could occur in up to $30 \%$ of CoM patients $[12,33,34]$. Thus, SLN biopsy has limitations and the ophthalmologist should be cautious when counseling the patient because results could potentially be a false negative.

\section{Indications for SLN Biopsy}

Based on a literature review, there are 61 reported cases of CoM that underwent successful SLN biopsies (table 2). Positive SLN were present in 10/61 (16\%) of cases, and negative results were present in 51/61 (84\%) cases. The mean average tumor thickness with a positive sentinel node was $4.8 \mathrm{~mm}$ (range $2.1-10 \mathrm{~mm}$ ), and with a negative sentinel node $2.4 \mathrm{~mm}$ (range $0.3-13 \mathrm{~mm}$ ). None of the positive lesions was less than $2 \mathrm{~mm}$ in thickness. The location of the CoM with positive SLN was nonlimbal in 9/10 (90\%) of cases.

High-risk features of CoM can be associated with either a higher risk of systemic metastasis and/or mortality or with a higher risk of nodal involvement (table 3). In our opinion, a SLN biopsy is indicated in the presence of $\geq 2$ high-risk clinical and/or pathological features for nodal metastasis. Those include: (1) clinical features: tumor thickness $>2 \mathrm{~mm}$ and nonlimbal location $[16,19,20,35]$, and (2) pathological features: ulceration and presence of $>1$ mitotic figure [36, 37].

Cohen et al. [14] reported that the SLN biopsy should be done subsequent to the conjunctival excision. Even though this was not done in our case, the authors agree with this suggestion as it allows for ample time for a critical review of the pathological specimens for high-risk features. An exception to that rule would be if the patient had a bulky disease $(>2 \mathrm{~mm}$ in thickness or had excision of a high-risk CoM at an outside institution with histopathologic criteria for SLN biopsy).

\section{Interpretation of SLN Biopsy in CoM}

If the nodal involvement is negative, the patient can be reassured that a subclinical metastasis was not detected. A periodic observation every 3 months for the first year after resection and every 6 months thereafter is recommended at our institute. Additionally, the patient 
Aziz et al.: Management of Conjunctival Melanoma: Critical Assessment of Sentinel Lymph Node Biopsy

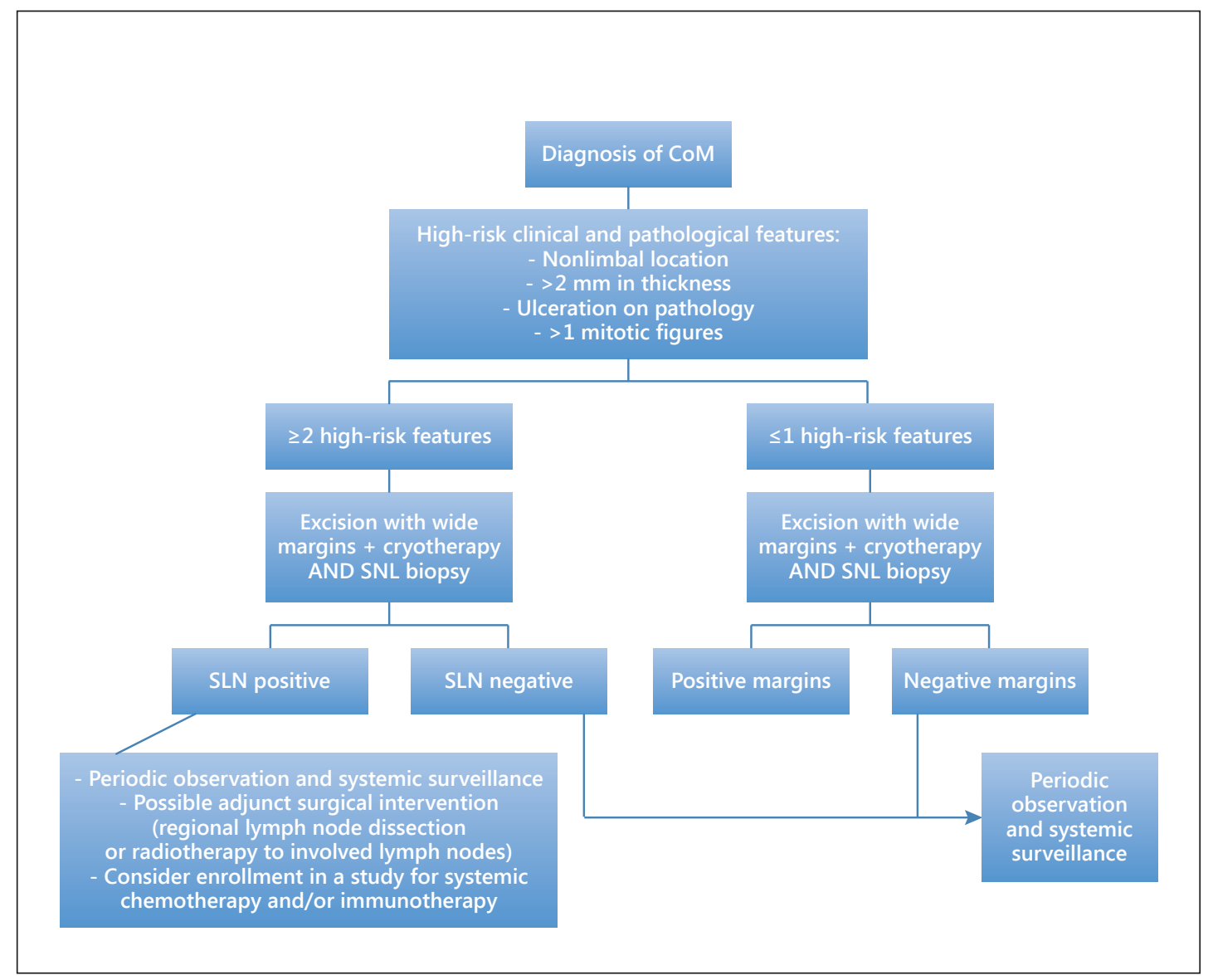

Fig. 2. An algorithm presenting a management plan for conjunctival melanoma based on high-risk clinical or pathological features.

should be educated about the disease and the signs as well as about the likelihood of recurrence based on the AJCC classification.

If the SLN were to be positive (in addition to the periodic ophthalmic observation), a referral to a medical oncologist with systemic surveillance is warranted. Further, adjunct surgical intervention including parotidectomy, neck dissection and possible postoperative radiotherapy to the regional lymph nodes should be considered. Enrollment in a study with systemic chemotherapy and/or immunotherapy should also be discussed with the patient. A conservative approach with PET scans can be performed every 6 months to evaluate for metastases. The algorithm is summarized in figure 2.

\section{Conclusion}

Patients that present with $\geq 2$ high-risk features (clinical or pathological) should be considered for SLN biopsy. SLN is a low morbidity procedure that allows for the staging of CoM identifying patients that could benefit from additional local intervention or systemic adjuvant therapy. Multi-institutional prospective studies will be needed to validate the efficacy of SLN biopsy in the staging of conjunctival melanoma. 


\section{References}

1 Vajdic CM, Kricker A, Giblin M, et al: Incidence of ocular melanoma in Australia from 1990 to 1998. Int J Cancer 2003;105:117-122.

-2 Isager P, Engholm G, Overgaard J, Storm H: Uveal and conjunctival malignant melanoma in Denmark 1943-97: observed and relative survival of patients followed through 2002. Ophthalmic Epidemiol 2006;13:85-96.

-3 Yu GP, Hu DN, McCormick S, Finger PT: Conjunctival melanoma: is it increasing in the United States? Am J Ophthalmol 2003;135:800-806.

-4 Paridaens AD, McCartney AC, Minassian DC, Hungerford JL: Orbital exenteration in 95 cases of primary conjunctival malignant melanoma. Br J Ophthalmol 1994;78:520-528.

5 Lommatzsch PK, Werschnik C: Malignant conjunctival melanoma. Clinical review with recommendations for diagnosis, therapy and follow-up. Klin Monbl Augenheilkd 2002;219:710-721.

6 Seregard S: Conjunctival melanoma. Surv Ophthalmol 1998;42:321-350.

7 Shields CL, Shields JA, Gunduz K, et al: Conjunctival melanoma: risk factors for recurrence, exenteration, metastasis, and death in 150 consecutive patients. Arch Ophthalmol 2000;118:1497-1507.

8 Finger PT, Sedeek RW, Chin KJ: Topical interferon alfa in the treatment of conjunctival melanoma and primary acquired melanosis complex. Am J Ophthalmol 2008;145:124-129.

-9 Ditta LC, Shildkrot Y, Wilson MW: Outcomes in 15 patients with conjunctival melanoma treated with adjuvant topical mitomycin C: complications and recurrences. Ophthalmology 2011;118:1754-1759.

10 Kurli M, Finger PT: Topical mitomycin chemotherapy for conjunctival malignant melanoma and primary acquired melanosis with atypia: 12 years' experience. Graefes Arch Clin Exp Ophthalmol 2005;243:11081114.

11 Karim R, Conway RM: Conservative resection and adjuvant plaque brachytherapy for early-stage conjunctival melanoma. Clin Experiment Ophthalmol 2011;39:293-298.

12 Werschnik C, Lommatzsch PK: Long-term follow-up of patients with conjunctival melanoma. Am J Clin Oncol 2002;25:248-255.

13 Baroody M, Holds JB, Kokoska MS, Boyd J: Conjunctival melanoma metastasis diagnosed by sentinel lymph node biopsy. Am J Ophthalmol 2004;137:1147-1149.

14 Cohen VM, Tsimpida M, Hungerford JL, Jan H, Cerio R, Moir G: Prospective study of sentinel lymph node biopsy for conjunctival melanoma. Br J Ophthalmol 2013;97:1525-1529.

15 Nijhawan N, Ross MI, Diba R, Ahmadi MA, Esmaeli B: Experience with sentinel lymph node biopsy for eyelid and conjunctival malignancies at a cancer center. Ophthal Plast Reconstr Surg 2004;20:291-295.

16 Rubinstein TJ, Perry JD, Korn JM, Costin BR, Gastman BR, Singh AD: Indocyanine green-guided sentinel lymph node biopsy for periocular tumors. Ophthal Plast Reconstr Surg 2014;30:301-304.

$\checkmark 17$ Maalouf TJ, Dolivet G, Angioi KS, Leroux A, Genin P, George JL: Sentinel lymph node biopsy in patients with conjunctival and eyelid cancers: experience in 17 patients. Ophthal Plast Reconstr Surg 2012;28:30-34.

-18 Savar A, Ross MI, Prieto VG, Ivan D, Kim S, Esmaeli B: Sentinel lymph node biopsy for ocular adnexal melanoma: experience in 30 patients. Ophthalmology 2009;116:2217-2223.

19 Wilson MW, Fleming JC, Fleming RM, Haik BG: Sentinel node biopsy for orbital and ocular adnexal tumors. Ophthal Plast Reconstr Surg 2001;17:338-344.

-20 Esmaeli B, Reifler D, Prieto VG, et al: Conjunctival melanoma with a positive sentinel lymph node. Arch Ophthalmol 2003;121:1779-1783.

21 Esmaeli B, Eicher S, Popp J, Delpassand E, Prieto VG, Gershenwald JE: Sentinel lymph node biopsy for conjunctival melanoma. Ophthal Plast Reconstr Surg 2001;17:436-442.

-22 Motomura H, Sakamoto M, Maruyama Y, Harada T, Ishii M: Sentinel lymph node biopsy in conjunctival malignant melanoma at the lacrimal caruncle: a case report. Osaka City Med J 2010;56:5-10.

23 Edge SB, Compton CC: The American Joint Committee on Cancer: the 7th edition of the AJCC cancer staging manual and the future of TNM. Ann Surg Oncol 2010;17:1471-1474.

-24 Yousef YA, Finger PT: Predictive value of the seventh edition American Joint Committee on Cancer staging system for conjunctival melanoma. Arch Ophthalmol 2012;130:599-606.

25 Shields CL, Kaliki S, Al-Dahmash SA, Lally SE, Shields JA: American Joint Committee on Cancer (AJCC) clinical classification predicts conjunctival melanoma outcomes. Ophthal Plast Reconstr Surg 2012;28:313-323.

26 Shields CL, Markowitz JS, Belinsky I, et al: Conjunctival melanoma: outcomes based on tumor origin in 382 consecutive cases. Ophthalmology 2011;118:389-395.

27 Tuomaala S, Kivela T: Metastatic pattern and survival in disseminated conjunctival melanoma: implications for sentinel lymph node biopsy. Ophthalmology 2004;111:816-821.

28 Esmaeli B, Wang X, Youssef A, Gershenwald JE: Patterns of regional and distant metastasis in patients with conjunctival melanoma: experience at a cancer center over four decades. Ophthalmology 2001;108:21012105.

29 Lim M, Tatla T, Hersh D, Hungerford J: Patterns of regional head and neck lymph node metastasis in primary conjunctival malignant melanoma. Br J Ophthalmol 2006;90:1468-1471.

-30 Morton DL, Wanek L, Nizze JA, Elashoff RM, Wong JH: Improved long-term survival after lymphadenectomy of melanoma metastatic to regional nodes. Analysis of prognostic factors in 1,134 patients from the John Wayne Cancer Clinic. Ann Surg 1991;214:491-499. 
Coit DG, Rogatko A, Brennan MF: Prognostic factors in patients with melanoma metastatic to axillary or inguinal lymph nodes. A multivariate analysis. Ann Surg 1991;214:627-636.

32 Tanabe KK, Reintgen D: The role of sentinel lymph node mapping for melanoma. Adv Surg 1997;31:79-103.

-33 Missotten GS, Keijser S, De Keizer RJ, De Wolff-Rouendaal D: Conjunctival melanoma in the Netherlands: a nationwide study. Invest Ophthalmol Vis Sci 2005;46:75-82.

-34 Tuomaala S, Eskelin S, Tarkkanen A, Kivela T: Population-based assessment of clinical characteristics predicting outcome of conjunctival melanoma in whites. Invest Ophthalmol Vis Sci 2002;43:3399-3408.

-35 Pfeiffer ML, Savar A, Esmaeli B: Sentinel lymph node biopsy for eyelid and conjunctival tumors: what have we learned in the past decade? Ophthal Plast Reconstr Surg 2013;29:57-62.

-36 Esmaeli B, Roberts D, Ross M, et al: Histologic features of conjunctival melanoma predictive of metastasis and death (an American Ophthalmological thesis). Trans Am Ophthalmol Soc 2012;110:64-73.

-37 Savar A, Esmaeli B, Ho H, Liu S, Prieto VG: Conjunctival melanoma: local-regional control rates, and impact of high-risk histopathologic features. J Cutan Pathol 2011;38:18-24. 